\title{
Escola, Competências 2.0 e Nativos Digitais: Um estudo exploratório com jovens portugueses
}

\section{School, skills 2.0 and digital natives: an exploratory study with portuguese pupils}

\author{
Antonieta Rocha*, Teresa Cardoso** \\ *Agrupamento de Escolas Eça de Queirós e LE@D - Laboratório de Educação a Distância e Elearning da Universidade Aberta, \\ **Universidade Aberta, Portugal - LE@D - Laboratório de Educação a Distância e Elearning
}

\begin{abstract}
Resumo
Pretendemos refletir sobre literacia digital, competências 2.0 de jovens e o papel da Escola no (eventual) incremento de ambientes digitais. Optámos por um estudo exploratório realizado com uma turma do curso vocacional de nível básico, numa escola de um agrupamento de Lisboa (Portugal), em 2013/2014. Recorremos a um questionário, complementado por observação participante. Concluímos que as competências digitais dos jovens inquiridos ainda carecem de maior desenvolvimento quanto ao conhecimento e utilização das ferramentas 2.0, sobretudo no contexto escolar. Importa, pois, (re)pensar novas estratégias e avançar um outro olhar sobre a prática docente, em particular nesta tipologia de cursos.

Palavras-chave: TIC, literacia digital, competências 2.0, jovens, Escola
\end{abstract}

\begin{abstract}
We intend to discuss students' knowledge and use of web 2.0 tools and the role of school in the improvement thereof. In this text we will present part of our exploratory study with students of a vocational course in a Lisbon school in 2013/2014. Methodologically, we opted to conduct a questionnaire completed in class with participant observation. The data analysis shows that students, while considered digital natives, lack some knowledge and use of 2.0 tools, in particular in school contexts, justifying a rethink of new strategies and another look at the teaching practice, particularly for this new type of course.

Keywords: ICT, digital literacy, skills 2.0, pupils, school
\end{abstract}

\section{Introdução}

Tratando este artigo de jovens - assumidamente nativos digitais -, importa perceber o papel da Escola no reconhecimento e dinamização do ambiente digital, decisivo na sociedade atual. Também com currículo diferenciado, a disciplina de Tecnologias da Informação e Comunicação (TIC) está - por decisão tutelar erradicada dos cursos vocacionais de nível básico, assumindo as aludidas competências como adquiridas, ainda que o currículo do ensino secundário profissional a integre - obrigatoriamente - visando, nomeadamente, o seu desenvolvimento para possibilitar uma literacia digital generalizada e desenvolver a capacidade de pesquisar, produzir e comunicar informação. Face aos pré-requisitos, exige-se um outro olhar perante jovens desmotivados, ainda que possuindo eventualmente conhecimento acumulado. Numa escola altamente equipada tecnologicamente, potenciando e proporcionando recursos materiais para a utilização das TIC, aliado à formação anterior do corpo docente, parecem estar reunidas as condições para uma utilização efetiva das ferramentas $2.0 \mathrm{em}$ sala de aula e, complementarmente, criar nos alunos o desafio e vontade para (novas) utilizações noutros contextos. Neste cenário propomo-nos obter respostas para algumas inquietações (a) poderão estes jovens ser considerados como nativos digitais? (b) será mesmo dispensável a disciplina de TIC? (c) evidenciam estes jovens as competências digitais 2.0 conforme presumido pela tutela? (d) qual o papel da Escola na dinamização dessas competências? (e) são os professores agentes ativos nessa utilização?

\section{Contextualização}

Em pleno século XXI em que a aprendizagem deverá ser em Rede e vincadamente marcada pelas competências digitais dos jovens, importa refletir acerca do seu (eventual) estatuto de nativos digitais, bem como analisar o papel da Escola e, em particular, o contributo dos docentes para a literacia dos mesmos, num cenário desafiador, em plena mudança e que se pretende passível de enfrentar um mercado de trabalho, também este em permanente mutação. Face a novas e alternativas modalidades de ensino para jovens, são estas algumas das temáticas que nos propomos refletir e problematizar seguidamente.

\section{Jovens 2.0}

Se, assumidamente, os jovens "have changed radically" (Prensky, 2001), esta geração foi cunhada pelo autor como "nativos digitais" e caracterizada como os nascidos na década de noventa, "capazes de executar várias tarefas em simultâneo, que têm acesso a uma série de novas tecnologias, demonstram confiança nas suas competências para utilizar tecnologias, recorrem à Internet como primeiro porto de escala para obter informação e [...] utilizam a Internet para fins educacionais assim como para outras actividades" (idem, p. 1).

Esta categorização (apenas assente na idade), ainda que não isenta de críticas (Helsper e Enyon, 2010) ou de estudos divulgando resultados contrários (Espanha e Cardoso, 2010), refere-se a jovens que evidenciam: (a) uma capacitação natural face ao mundo digital "pensando e processando a informação de forma 
diferente" e (b) uma aptidão para o hipertexto e a imagem (Prensky, 2010).

Também, e conforme os resultados de estudos recentes (cf. por exemplo: Pisa, 2015), os jovens portugueses reduziram as suas quotas de baixo desempenho em matemática (OECD, 2013, p. 4). Contudo, revelaram-se melhores a usar o seu conhecimento para "planear e executar" uma solução do que a adquirir, eles mesmos, esse conhecimento, a questioná-lo, a gerar e a experimentar alternativas (Lopes, 2014, p. 1), de onde emerge a necessidade de incrementar o raciocínio, a aprendizagem autodirigida e a verdadeira resolução de problemas. (2014, p. 2).

De igual forma, e se atentarmos nas competências digitais, os jovens portugueses evidenciam "competências e actividades online um pouco acima da média europeia" (Ponte, 2010, p. 1), o que configura o cenário ideal para o sucesso na Escola, que deverá expectavelmente - acompanhar estes desafios.

\section{A Escola e o Ambiente 2.0}

Face ao perfil dos jovens importa analisar até que ponto a escola atual está preparada para lhes responder adequadamente. Até porque cada vez mais o mercado de trabalho necessita de receber quadros devidamente preparados, sobretudo face a diferentes preocupações consubstanciadas em medidas que visem "colmatar a falta de competências digitais na Europa" (Carneiro, 2014, p. 2), as recomendações de diferentes entidades oficiais e internacionais - OCDE e tutela - legitimam uma Escola atual e atualizada. A nível tecnológico, as escolas portuguesas estão equipadas, a partir de iniciativas que remontam a 1985 , como o projeto CRIE (2008) em que se propunha "promover e dinamizar o uso de computadores, redes e Internet nas escolas" (Despacho $\mathrm{n}^{\mathrm{o}}$ 18871/2008). Porém, e pese embora o elevado esforço financeiro nesse apetrechamento efetivado, partilhamos das preocupações e inquietações de vários autores (Sampaio e Coutinho, 2012), já que “a qualidade do uso das TIC não está diretamente relacionada com a tecnologia em si, mas com a forma como essa tecnologia é aplicada pelo professor em contexto de sala de aula" (p. 13). A mudança terá que passar inegavelmente pelos professores, enquanto agentes ativos e predispostos para este novo desafio.

$\mathrm{Na}$ tentativa de um quadro integrador, por exemplo, a UNESCO, no que às TIC diz respeito, mapeou as capacidades "específicas a serem adquiridas pelos professores" (UNESCO, 2009, p. 4). Tentando dar cumprimento às aludidas diretrizes, por iniciativa ministerial (Portaria No 731/2009 de 7 de julho), foi regulamentado o Sistema de Formação e de Certificação em Competências TIC para docentes em exercício, tendo como objetivos tanto a promoção e generalização das competências digitais e pedagógicas como o seu reconhecimento, tentando ultrapassar "os principais factores inibidores da modernização tecnológica do sistema educativo" (p. 4340). Assim, parecem-nos estar reunidos os pressupostos à implementação do aludido ambiente digital - transversalmente - a toda a oferta educativa vigente.

\section{A Oferta Formativa Portuguesa}

Gizando uma caracterização do sistema educativo português e a par com a oferta educativa "convencional", os elevados níveis de insucesso escolar reclamam respostas alternativas.

Detendo-nos no ensino diurno, desde cedo a via formal configurava-se como a única e determinante, quer para o ensino básico - com currículo único -, quer para o secundário - com os cursos científicoshumanísticos.

Porém, e tentando responder a quem desejava optar pela aproximação ao mundo profissional e ingressar no mercado de trabalho, o ensino secundário oferece, desde 1998, cursos profissionais.

No entanto, o nível de insucesso, gradualmente crescente nos segundo e terceiro ciclos do ensino básico, justifica a criação de uma via alternativa - os cursos vocacionais - de nível básico (2012) e nível secundário (2013).

As suas características diferenciadas, aliadas à crescente adesão dos jovens (atualmente 24 mil alunos), justificou a sua generalização (em março de 2015) e o nosso olhar mais atento, já que neles recai o estudo agora apresentado.

\section{Os Cursos Vocacionais de Nível Básico}

Tendo como destinatários alunos com mais de 13 anos, com duas retenções no mesmo ciclo ou três em ciclos diferentes" (Portaria 292-A/2012 de 26 de setembro), os cursos vocacionais de nível básico pretendem "assegurar a inclusão de todos no percurso escolar" (para. 2), garantindo "uma igualdade efetiva de oportunidades, consagrando alternativas adequadas e flexíveis, que preparem os jovens para a vida, dotandoos de ferramentas que lhes permitam vir a enfrentar no futuro, também, os desafios do mercado de trabalho." (para. 2) Porque destinados a jovens, comprovadamente "zangados" com a escola e com um sistema de ensino convencional e maioritariamente teórico, estes cursos apresentam "uma estrutura curricular organizada por módulos" ( $\mathrm{N}^{\mathrm{o}} 1$ do Art. $^{\mathrm{o}}$ 5 $\left.^{\circ}\right)$, com um plano de estudos constituído por 3 componentes de formação: (a) Geral Português, Matemática, Inglês e Educação Física; (b) Complementar - Ciências Sociais (História e Geografia) e Ciências do Ambiente (Ciências Naturais, FísicoQuímica); (c) Vocacional (3 áreas) com prática simulada desenvolvida em empresas que desenvolvam as atividades vocacionais ministradas $\left(\mathrm{cf}\right.$. Art. $\left.{ }^{\circ} 5^{\circ}\right)$.

Assim, e se o enfoque assenta na prática, com estreita aproximação ao mercado de trabalho, ainda que "por observação" - fator distintivo e de sucesso destes cursos, porque motivante para os alunos - as novas tecnologias estão erradicadas do seu plano curricular. Paradoxalmente, encontramo-las - obrigatoriamente no ensino secundário profissional visando, nomeadamente, o seu desenvolvimento para possibilitar uma literacia digital generalizada e desenvolver a capacidade de pesquisar, produzir e comunicar informação (Direcção-Geral de Formação Vocacional, 2004/2005, p. 2), a assunção, por parte da tutela de que "a maioria dos jovens já dominam os computadores", o 
incremento das aludidas competências 2.0 apenas se consagrará caso os próprios alunos as tenham adquiridas e/ou os professores as incrementem em sala de aula, um foco do nosso estudo.

\section{Metodologia}

Alicerçada nos marcos teóricos supra e a fim de obter respostas para algumas inquietações - (a) poderão os jovens [do curso vocacional de ensino básico] ser considerados como nativos digitais? (b) será mesmo dispensável a disciplina de TIC? (c) evidenciam estes jovens as competências digitais conforme presumido pela tutela? (d) qual o papel da Escola na dinamização dessas competências? (e) são os professores agentes ativos nessa utilização? -, considerámos ser o estudo exploratório o mais adequado para "definir as questões ou hipóteses para uma investigação posterior" (Meirinhos e Osório, 2010, p. 9) e procurar informações propiciadoras do estabelecimento de relações causaefeito, características dos aludidos estudos exploratórios que permitam "orientar estudos posteriores" (idem, p. 9).

\section{Participantes}

O nosso estudo exploratório incidiu numa turma do curso vocacional de nível básico, numa escola de um agrupamento de Lisboa (Portugal), no ano letivo de 2013/2014.

Apenas circunscrita aos alunos da única turma existente, e sendo que a mesma iniciou com 24, o nosso estudo recai sobre os 17 à data a frequentar o curso, maioritariamente masculinos (10) e com idades compreendidas entre os 16 (7) e os 18 anos (4).

\section{Instrumentos e Materiais}

Para a concretização dos instrumentos de recolha de dados, optámos privilegiadamente por um inquérito por questionário, com 18 perguntas fechadas e 4 abertas, complementado pela nossa experiência e observação participante, uma vez que uma das investigadoras foi acompanhante de prática simulada e professora de uma área vocacional - e que impulsionou, sempre que adequadas, as competências digitais, bem como a utilização da plataforma Moodle enquanto recurso diário em sala de aula.

\section{Procedimento}

O referido inquérito por questionário, após validação, foi aplicado presencialmente, a fim de prevenir eventuais constrangimentos técnicos, e tratado com recurso ao Microsoft Excel 2007 para sistematização dos resultados das respostas fechadas em quadros de frequências absolutas e relativas e por análise de conteúdo, tanto para as respostas abertas, como para os resultados da nossa observação.

\section{Resultados}

Tentando perceber o tipo de utilização que os inquiridos fazem da Internet, apenas um inquirido não tem computador nem acesso à Internet em casa, enquanto que os restantes, ou seja, a maioria destes jovens (16) a utiliza, em média, 1 a 3 horas diárias, sendo que 4 gastam entre 4 a 6 horas e 6 a partir de 7 horas por dia, preferencialmente em casa (15), seguido da escola e preterindo os locais públicos.

$\mathrm{O}$ acesso é feito maioritariamente através do computador portátil de casa (11), seguido do telemóvel (8) e do computador da escola (4).

A Internet é maioritariamente utilizada para ouvir música (15) e aceder a Redes Sociais (14), ver filmes e elaborar trabalhos escolares (13), jogar e comunicar com colegas (12), fazer pesquisas (11) e, por último, para ler notícias (7).

No que concerne ao termo Web 2.0, e pese embora na nossa Área Vocacional a temática tenha sido abordada, apenas 9 dos 17 jovens declararam já ter ouvido falar ainda que não se sintam capazes de o explicar enquanto que 6 assumiram não o conhecer.

Entendendo importante tentar perceber qual o grau de conhecimento das ferramentas 2.0, elegemos 12, representantivas de uma diversificação e finalidades várias. Os resultados obtidos permitem-nos concluir que a maioria destes jovens (10) desconhece os ambientes virtuais e os podcast (9), enquanto que $1 / 3$ dos inquiridos declara não conhecer o Wordle (6) nem os livros digitais/e-books (5). Dos jovens que declararam conhecer estas ferramentas, a maioria não utiliza os blogues (15), a plataforma Moodle (13), a criação de sites (11) e os livros digitais/e-books (10). Ainda que com valores menos significativos, também o Wordle (9), os podcast (8) e as ferramentas Google (6) não são utilizadas.

Por seu turno, o Youtube é a ferramenta utilizada pela totalidade dos nossos jovens (17), seguida das redes sociais (16). Ainda é de realçar que 14 dos nossos inquiridos declararam utilizar as wikis, seguida das ferramentas Google (11) e da partilha de fotos (10), surgindo as primeiras ferramentas que poderão ser diretamente relacionadas com a atividade escolar.

Tentando perceber agora que tipo de utilização fazem das mesmas, a fim de podermos tentar confirmar/infirmar se as utilizam em contexto escolar ou apenas pessoal, constatamos que algumas ferramentas são utilizadas preferencialmente em contexto pessoal - Redes Sociais e Youtube (15), partilha de fotos (9) e ferramentas Google (6). Também e ainda que com valores pouco significativos (mas os mais elevados para essas ferramentas), 4 jovens assumiram utilizar os ambientes virtuais, a criação de sites e os livros digitais/e-books em contexto pessoal.

Se na escola, e ainda que não para tarefas escolares, os valores obtidos não tenham sido muito significativos - exceção feita às ferramentas Google (4), blogues (3) e Wordle, podcast, criação de sites e wikis (2), as wikis são utilizadas por 10 jovens para a realização de tarefas escolares. Ainda para a realização de tarefas escolares 6 jovens elegeram o Wordle enquanto que 5 a Moodle 2.0.

Contrariamente à utilização da Internet, maioritariamente para fins lúdicos, estes jovens assumiram as ferramentas Web 2.0 preferencialmente para utilizações ligadas à escola (10) - pesquisa e elaboração de trabalhos escolares - e apenas em segundo plano o seu cariz lúdico - comunicar com 
amigos (8). A utilização para trabalhos em grupo aliada à facilidade de acesso acolheram a resposta de 7 jovens e apenas para 5 a partilha de informação se afigurou como determinante. Por último, a motivação e outras razões - pesquisa de jogos e "não uso" - foram as eleitas para 2 jovens.

Incidindo a análise sobre a plataforma Moodle 2.0, utilizada por nós em sala de aula, verificámos, pela nossa observação participante, que os alunos - divididos em 3 grupos - assumiram uma postura diferente perante a mesma. Isto é, excetuando um grupo a quem não foi possível uma prática tão efetiva quanto a desejada, por força de impedimentos tecnológicos, um segundo grupo utilizava-a por "obrigação" enquanto o terceiro a usava com autonomia (sendo visível a sua motivação). Verificámos de igual modo que apenas 5 já tinham trabalhado com a plataforma anteriormente, ainda que 11 dos 17 jovens já a conhecessem.

Analisando as perceções acerca desta plataforma, e se para a maioria dos jovens (8) não se afigura viciante, o aspeto desafiante não acolheu consenso, já que foi considerada como "Algo" e "Pouco" desafiante, ambas com 6 respostas. Quanto aos restantes aspetos motivante, útil, interessante e importante - foi a perceção "algo" que acolheu a maioria das respostas.

Apenas 1 jovem sente vontade de voltar a utilizar a Moodle 2.0; na verdade, e excluindo uma não resposta, para 15 jovens a plataforma não foi suficientemente motivadora e apelativa a ponto de perpetuar a sua vontade de novas utilizações. Como justificações apresentadas, e se para o jovem que respondeu afirmativamente a facilidade de utilização justifica uma futura utilização, os restantes declinaram-nas (respondendo negativamente) não the reconhecendo interesse, utilidade e necessidade.

Consequentemente e perante a hipótese de recomendação a um amigo, os dados obtidos são sensivelmente idênticos. Excluídas 2 não respostas, apenas 2 jovens o fariam porque a mesma (i) se afigura útil e com acesso rápido e (ii) iria permitir mais conhecimento.

\section{Discussão}

Os dados obtidos para a primeira parte deste questionário, em que se pretendia caracterizar a utilização e o acesso à Internet, merecem-nos algumas reflexões. Dado que de público jovem se trata, pensamos ser a carga horária do curso e o elevado número de horas que passam na escola, a razão pela qual o rácio de utilização da Internet não se assume mais elevado. De acordo com as respostas, podemos confirmar que o local de acesso por excelência é em casa, através do computador portátil, para utilizações maioritariamente lúdicas - ouvir música e ver filmes - e apenas num nível abaixo as atividades que se prendem diretamente com aspetos científicos e/ou escolares. Também aqui não podemos deixar de refletir: sendo certo que a Internet apresenta atualmente e ainda alguns riscos, são irrefutavelmente assumidas as suas vantagens em contexto escolar. Porém, estes dados revelam-nos uma realidade um pouco diferente, o que vem reforçar as nossas inquietações quanto à sua não generalização em sala de aula.

Também os resultados obtidos para o desconhecimento do termo Web 2.0 permitem acentuar a inevitável mudança de estratégias - por parte dos professores que lecionam estes cursos - para que sejam eficazes a ponto de prender a atenção destes jovens, atenção que facilmente se dispersa e que deve ser ancorada em atividades práticas e radicadas em analogias óbvias com a vida real, ao arrepio de uma teorização que não se afigura eficaz nem eficiente para estes jovens alunos.

Tendo como objetivo a triangulação entre o (des)conhecimento e o contexto em que a utilização é feita, podemos concluir que algumas das ferramentas que poderiam e deveriam ser utilizadas para a realização de tarefas escolares (mesmo em contexto de sala de aula), são utilizadas apenas e preferencialmente em contexto pessoal, o que poderá indiciar que os docentes ainda não as exploram. Também, e na senda do já concluído, constatamos que estes jovens reconheceram, nesta questão, o Wordle e a Moodle 2.0 por nós utilizadas em sala de aula. Ainda não deixa de ser interessante concluir que estes jovens na escola, fora da realização de tarefas escolares, tenham declarado utilizar as ferramentas Google e os blogues. Face a estes resultados, complementados com a nossa observação, algumas reflexões imperam: os jovens utilizam o seu tempo, fora da sala de aula, conectados preferencialmente com as Redes Sociais, se a utilização de blogues poderá ser justificada pelo fenómeno da comunicação com amigos, resta-nos alguma dúvida quanto às ferramentas Google. Esta dúvida reside na incerteza sobre se os jovens têm um conhecimento concreto e pleno de que ferramentas nos estamos a referir ou se apenas as associaram ao e-mail. Estas são algumas questões que se nos afiguram importantes e interessantes para futuras investigações. Estes jovens assumem estas ferramentas como prioritariamente destinadas a utilizações ligadas à escola, ainda que as mesmas não sejam incrementadas em sala de aula. Mas, e sendo que deveriam e poderiam estar presentes numa literacia escolar e até na rotina da sala de aula, até pelos resultados agora obtidos, a realidade é ainda bem diferente.

Acreditando nas potencialidades da Internet e tentando usufruir das vantagens das ferramentas 2.0, na nossa área vocacional, sempre incentivámos a sua utilização e elegemos prioritariamente (de forma obrigatória) a plataforma Moodle. Porém, podendo assumir-se como uma avaliação positiva, estes jovens não estão totalmente rendidos nem convencidos das suas vantagens.

Sendo certo que a maioria destes jovens já conhecia a Moodle, apenas menos de $1 / 3$ já a tinha utilizado. Assim, e ainda que desconhecêssemos estes dados, considerando que esta é a plataforma implementada na generalidade das escolas aliada às suas vantagens inequívocas - pelo menos para nós -, optámos por adotá-la não só enquanto repositório dos materiais por nós apresentados, mas também como forma de interação e meio privilegiado de entrega dos trabalhos realizados 
pelos alunos, tentando que a mesma se constituísse enquanto portefólio digital.

Pese embora a nossa observação, que nos dá indicadores de algum interesse, estes jovens não a consideraram tão apelativa ao ponto de ponderarem futuras utilizações. A par da evidente desmotivação, o fator imediatista impera nestas respostas. Na verdade, a justificação negativa prende-se diretamente com a aliança irrefutável entre Moodle e a escola. Também esta associação se afigura importante para reflexão. Sendo certo que não é expectável que dela façamos utilização em contexto pessoal, os jovens que inquirimos não reveem valor em nada que se radique no contexto escolar; também, e complementarmente, as reduzidas saídas escolares deste curso podem justificar o desprendimento dos inquiridos.

\section{Conclusões}

Pelo exposto, pensamos poder concluir que estes jovens revelam características que permitem ser considerados como nativos digitais. Ainda que desprovidos de uma disciplina TIC, os mesmos evidenciam algum conhecimento digital; porém, as suas competências digitais 2.0 estão aquém do que seria expectável para quem possui, no mínimo dez a onze anos de escolaridade e que ingressará, muito em breve, no mercado de trabalho. Também, os professores se parecem afigurar enquanto agentes passivos, ao arrepio do desejável, não propiciando, em sala de aula, as experiências e o contacto com as aludidas ferramentas que estes jovens utilizam, mas maioritariamente em contexto pessoal. Assim, será desejável que a Escola se assuma mais dinâmica e interventiva - com a introdução de uma disciplina TIC - e efetivo papel dos professores; em suma, defendemos o (re)pensar de novas estratégias e um outro olhar sobre a prática docente, em particular para esta nova tipologia de cursos.

\section{Referências}

Carneiro, P. (2015). Memorando de Cooperação para a Implementação da Coligação Portuguesa para a Empregabilidade Digital. Fundação para a Ciência e Tecnologia.

Casa dos Bits. (2011). Ministério da Educação estuda extinção da disciplina de TIC. Casa dos Bits. http://tek.sapo.pt/noticias/computadores/ministerio_da educacao estuda extincao da dis 1197734.html
Decreto-Lei $\mathrm{n}^{\mathrm{o}}$ 4/98 de 8 de janeiro do Ministério da Educação. Diário da República: I Série - A, No 6 (1998).

Direcção-Geral de Formação Vocacional. (2004). Programa de Tecnologias da Informação e Comunicação.

Helsper, E. \& Enyon, R. (2010). Digital Natives: where is the evidence? British Educational Research Journal, Vol. 36, No 3, Jun. 2010, pp. 503-520.

Lopes, M. (2014). Alunos portugueses melhores a executar do que a pensar em abstracto. Jornal Público online. http://www.publico.pt/sociedade/noticia /alunos-portugueses-melhores-a-planear-e-executardo-que-a-pensar-em-abstracto-1630545

OECD. (2013). PISA 2012 Results in Focus.

Prensky, M. (2001). Digital Natives, Digital Immigrants. On the Horizon, MCB University Press. Vol 9 No 5.

Ponte, C. (2010). As crianças mais novas ainda precisam de desenvolver mais competências digitais. EU Kids Online.

Portaria $n^{0} 731 / 2009$ de 7 de julho do Ministério da Educação. Diário da República: I Série - $\mathrm{N}^{\mathrm{o}} 129$ (2009).

Sampaio, P. \& Coutinho, C. (2012). Ensinar Matemática com TIC: em busca de um referencial teórico. Revista Portuguesa de Pedagogia, Ano 46-II, 2012, 91-109.

UNESCO. (2009). Padrões de Competência em TIC para Professores. 